Spassov, N., GeraAds, D., Hristova, L., Markov, G. N. 2019. The Late Miocene mammal fauna from Gorna Sushitsa, Southwestern Bulgaria, and the Early/Middle Turolian transition. Neues Jahrbuch für Geologie und Paläontologie, 291(3): 317-350.

\begin{abstract}
We describe here the Turolian (late Miocene) faunas from several fossiliferous localities at Gorna Sushitsa (South-Western Bulgaria). The composite fauna is typical for the Turolian of the Balkan. The stratigraphically lowermost locality, GS2, yields more primitive stages of Adcrocuta eximia and Paramachaerodus orientalis than at Pikermi, and could be an early Turolian one, very close to the lower / middle Turolian transition. The faunas from stratigraphically higher localities are characteristic of the Middle Turolian and display (especially those from the upper levels), the features of the typical Pikermi fauna. The Gorna Sushitsa faunas indicate a xerophytic open woodland/shrubland at that time.
\end{abstract}

Key words. Mammalia, late Miocene, Bulgaria, early/middle Turolian transition

\title{
Introduction.
}

Chalicotheres were the first Late Miocene mammals reported from the region of Gorna Sushitsa (Sandanski District, S. W. Bulgaria) (BAKALOV 1955). BAKALOV \& NiKOLOV (1963) listed from there : Ancylotherium pentelicum, Chalicotherium goldfussi, Hipparion mediterraneum, Hipparion matthewi, Helladotherium duvernoyi, Tragoceras [sic] amaltheus, Palaeoreas lindermayeri, and Mesopithecus pentelici. The exact provenance of the fossil material that they described is not known with precision, but they were found in the ravine, to the west of the village. The species noted in the check-list of NIKOLOV (1985) are as follows: Ancylotherium pentelicum, Chalicotherium goldfussi, Hipparion theobaldi (the name of this Asian taxon was probably used for H. brachypus), Hipparion mediterraneum, Tragoceras amaltheus (now Tragoportax amalthea), 
Mesopithecus pentelicus and Palaeoreas lindermayeri. Recent surveys in this area by two of us (NS and DG) in 2004-2005 resulted in the discovery of a number of fossiliferous spots (localities) with Turolian fossil mammals in the Neogene sediments of the deep ravine that cuts through the Neogene sediments West of the village of Gorna Sushitsa (GERAADS et al. 2006; SPASSOV et al. 2006), showing that Gorna Sushitsa cannot be regarded as a single locality, but instead as a set of localities of somewhat different ages. Excavations in some of these localities were undertaken by us from 2005 onwards. In spite of the steep slopes and highly consolidated sediments that render extraction difficult, we were able to collect some 400 mammalian fossils, significantly increasing the composite faunal list from this site, and expanding the knowledge of the biostratigraphy of the fossiliferous localities and the palaeoenvironment. They are described below, and their ecological, biochronological and zoogeographical implications are briefly discussed.

\section{Material and abbreviations}

GS - Gorna Sushitsa fossiliferous site (the following number refers to the exact locality; see Fig. 1). KMP - Kovachev Museum of Paleontology (branch of the National Museum of Natural History, Sofia), Assenovgrad, Bulgaria.

MNHN - Muséum National d'Histoire Naturelle, Paris

NHMUK - Natural History Museum, London

NMNHS - National Museum of Natural History at the Bulgarian Academy of Sciences, Sofia UT(DG) - Eberhard Karls University, Tübingen (Department of Geosciences)

The chalicothere fossil material collected by P. BAKALOV and I. NIKOLOV is stored at the Museum of Paleontology and Historical Geology of the St. Kliment Ohridski Sofia University (GERAADS et al. 2001; 2006). The Mesopithecus material from the old collections (KoUfOS et al. 2003) is stored in the NMNHS with the suffix FM. 
Most of the fossil material described here is stored in the NMNHS and is accessioned with the prefix GS, while that collected by the team of M. BÖHME is stored in the UT(DG) with the abbreviation GPIT.

$\mathrm{APD}=$ antero-posterior diameter; dist. $=$ distal; $\mathrm{L}=$ length; prox. $=$ proximal; $\mathrm{TD}=$ transverse diameter; $\mathrm{W}=$ width, $\mathrm{H}=$ height. Measurements are in millimeters.

The fossil site of Gorna Sushitsa. The fossiliferous deposits crop out in the ravine that cuts into the Neogene sediments immediately to the west of the village of Gorna Sushitsa, at about $41.555^{\circ} \mathrm{N}$, $23.384^{\circ} \mathrm{E}$ (Fig. 1). More than ten fossiliferous localities (the numbering in the text follows the numbering noted on the map (Fig. 1) were recognized from 2004 onwards on both sides of the ravine, at various elevations above the river. According to local people, the fossils collected and described by P. BAKALOV and I. NIKOLOV, came from the same place, but the exact localities remain unknown. The sediments were deposited in the Sandanski Graben, which is composed of the Neogene terrestrial deposits of the Sandanski and Kalimantsi Formations (KoJUMDGIEVA et al. 2002). They are represented by grey to whitish, greyish-green and yellowish sandy-clays and aleurite-clays, with intercalations by unsustained beds, interlayers and lenses represented by sands, gravel sands or aleurite-sandy-calyces of different thickness with alluvial-proluvial origin (KOJUMDGIEVA et al. 1982; ZAGORCHEV 2007). They were also included in the Strumyani genetic lithocomplex, whose estimated time of accumulation is based on its mammalian faunas and corresponds to the late early Turolian and to the middle Turolian (TZANKOV et al. 2005; SPASSOV et al. 2006). The fossiliferous sediments which yield the mammalian fauna of Turolian age, described here, fall into the Orange interval of subsection C of the Gorna Sushitsa late Miocene continental deposits described by BöHME et al. (2018) which are included by these authors in the Kalimantsi Formation.

The thickness of the fossiliferous sediments in the studied part of the outcrop of the ravine is more than $50 \mathrm{~m}$. The lowermost fossiliferous localities GS12 and GS2 are located downstream, near the 
level of the riverbed; localities GS3, GS7 and GS9 are higher, at roughly the same stratigraphic level. The uppermost localities are, in decreasing age, GS10, GS8, GS11 and GS1 on the right bank of the ravine, and GS6 on the left one (Fig. 1). The stratigraphic position of the localities and their magnetostratigraphic age are presented in BÖHME et al. (2018; Fig. 4 and tab. 2).

\section{Systematic palaeontology}

Order Rodentia BowDICH, 1821

Family Hystricidae FISCHER, 1817

Hystrix primigenia (W AGNER, 1848)

A calcaneus GS2-2566 (L max. = 48.3; TD max. from the lateral tuberosity of incertion till sustentaculum tali $=26.2$; Fig. 2, L) has the morphology and size of the large Hystrix primigenia (see in KOVACHEV 2012); this species is not abundant in the palaeozoocoenoses, but often present in the late Miocene faunas of the Balkans. In Bulgaria it is known from the Turolian of Hadjidimovo-1, Kalimantsi and Strumyani-2 (GERAADS et al. 2010).

Order Primates LinNAEUs, 1758

Family Cercopithecidae GRAY, 1821

Subfamily Colobinae BLYTH, 1863

Mesopithecus pentelicus WAGNER, 1839

Gorna Sushitsa is noted as a Mesopithecus site by BAKALOV \& NIKOLOV (1962), but which material really comes from this locality is not explicitly indicated in the text and in their plate 82. An upper tooth series of a juvenile individual from Gorna Sushitsa (not figured in BAKALOV \& NIKOLOV, 
1962) was examined by E. DELSON in 1973 in the Univ. of Sofia (E. DELSON, in litt.). In the 70s, the old collection of Bulgarian Mesopithecus described by BAKALOV \& NIKOLOV (1962) was moved to the NMNHS, but in this process the noted maxillary was damaged and some labels were changed by mistake, so that it was wrongly labelled and mentioned by Koufos et al. (2003) as from Kromidovo (this specimen, NMNHS-FM1530 include right and left DP4-M1, and right P4 erupting: E. DELSON, in litt.). The teeth of this probably female individual have the morphological and metric characteristics of the Pikermi sample. Koufos et al. (2003) also described as from Gorna Sushitsa two partial maxillae, with C-M2 (FM-1527) and with P3-P4 (FM-1529), which are in fact from Kalimantsi (E. DELSON, in litt.).

Mesopithecus is well represented in the localities of Gorna Sushitsa by more than 20 cranial and postcranial remains (Fig. 2A-K and Tables 1-4), found during our excavations in six different localities, namely GS1, GS3, GS4, GS7 and especially in the upper levels of the section, at GS8 and GS11. The material includes: a fragment of skull from a small sized individual from GS1 (subsequently lost); fragment of skull with mandible of an old female, GS3-3151; incomplete humerus, radius and ulna of an adult male, GS4-3150; several bones from the pes from GS7 - distal metatarsal fragments (GS7-3196A-3196D), calcaneus (GS7-3195A, Fig. 2J), talus (GS7-3195B, Fig 2K) and a navicular bone (GS7-3195C) from the same individual, (a fragment of humerus and a similar in size calcaneus in UT(DG), are probably also from the same individual.); remains of probably three females - a right maxillary fragment of a subadult individual with P2-M3 (GS8-2687, Fig. 2A), a mandible of an old female with all incisors and right c-m2, GS8-2685 (Fig. 2E-F), and a mandible fragment of a (different?) adult individual with p3-m2, GS8-3686 (Fig. 2G); remains from at least two individuals (male and female) from GS11 are stored in the UT(DG) (unnumbered): a complete mandible of a male individual, left female humerus and radius (max. prox diameter $=12.3$ ), left radius (male: max. proximal diameter $>14$; max. length $=160 \mathrm{~mm}$ ), left ulna (max. breadth at coronoid process $=17,2$ ) and a fragment of scapula. A complete mandible of a large male was found 
at GS11 (unnumbered - UT(DG)) (length of the mandible from condyle to rostrum $=88 \mathrm{~mm}$; width over condyles $=70.1 \mathrm{~mm}$; max. height of the mandibular ramus to processus coronoideus $=56 \mathrm{~mm}$, to condyle $=51 \mathrm{~mm})($ Fig. $2 \mathrm{~B}-\mathrm{D})$.

The collum of the talus GS7-3195B, is rather elongated, as usual in Mesopithecus, slightly more so than in Macaca and slenderer than in Papio. The maximal oblique length of the talus (= AS4 length in AlBA et al. 2013) is $27 \mathrm{~mm}$, very close to that of M. p. pentelicus from Moncucco, Italy (latest Turolian) (ALBA et al. 2013). The calcaneus (GS7-3195A) is relatively massive, the distal part of the corpus is short (shorter than in Papio); the tuber calcanei is deep in dorso-plantar direction; max. length $=38 \mathrm{~mm}$, max. medio-lateral width $=20.3$. Its size (like that of the talus) exceeds that of three female skeletons (33-33.5 × 18.5 - 19.6) of Mesopithecus "delsoni" from the early Turolian of Hadjidimovo, Bulgaria (Koufos et al. 2003) and indicates a male individual.

According to one of us (N.S.) the Mesopithecus remains from GS display the features (shape of P3P4 cusps, shape of the mandibular symphysis) of the Pikermi stage of Mesopithecus, rather than the morphology observed in the older late Miocene localities (see in: KoufOS et al. 2003; SPASSOV et al. 2018). The metric data (especially teeth, mandibles, long bones (Tables 1-4) also show similarities with the population from Pikermi, which has in general smaller dimensions than the older Balkan populations from Ravin des Zouaves-5(Greece), Hadjidimovo (Bulgaria) and Vathylakkos (Greece) (BONIS et al. 1990; KoufOS et al. 2003; KoufOS 2009). The size and morphology of the GS population is virtually identical with Mesopithecus pentelicus from the type locality of Pikermi. ALBA et al. (2015) refer the early to middle Miocene forms to a single species with two subspecies, the type subspecies from Pikermi, M. p. pentelicus, and the one from Ravin des Zouaves-5, M. p. delsoni. The case could be more complicate (see KoufOS 2009), but in any case the forms $M$. pentelicus and M. delsoni with at least one intermediary stage among them in time (at the early/middle Turolian boundary could be regarded as chronoforms of a paleontological megaspecies 
with more clear taxonomic differences only between the oldest and the youngest populations (SPASSOV et al. in press).

Order Carnivora BowDICH, 1821

"Ictitheres". The taxonomy of the large group of carnivores called "Ictitheres" is still controversial, after more of a century of investigations (for discussion see WERDELIN \& SOLOUNIAS 1991;

ANDERSON \& WERDELIN 2005; SEMENOV 2008). Here we adopt the taxonomical concept proposed by SEMENOv (1989), who divided this possibly polyphyletic group into two high rank taxa, Ictitheriinae TrOUESSART, 1897 and Hyaenotheriini SEMENOV, 1989, respectively assigned to the Viverridae and Hyaenidae.

Family Viverridae GRAY, 1821

Subfamily Ictitheriinae TROUESSART, 1897

Ictitherium cf. viverrinum ROTH \& WAGNER, 1854

Material: a well preserved rostral part of skull (GS2-3165) of a relatively large "ictithere" with complete right tooth row (I1-M2) and left tooth row with C-M2 (Fig. 3D-E; Table 5).

The cheek-teeth length and carnassial tooth are too small for a Hyaenotheriini (sensu SEMENOV 1989), while the molar length and especially the absolute and relative size of M2 are too large for this tribe and indicate a member of the Ictitheriinae (see SEMENOV 1989: tables 2,4,6,8). The tooth size is large for Protictitherium and the molar angle (the angle between the line of the labial premolar surface and the labial surface of molars, sensu SEMENOV 1989, 2008) is too small (about $60^{\circ}$ ) for Thalassictis, in which it is about $80^{\circ}$. The size is small for Ictitherium pannonicum and is similar to Ictitherium viverrinum, known from a number of Turolian localities from Southern Europe to China (Fig. 5). The $\mathrm{P} 4$ protocone in the latter species generally protrudes anteriorly to the parastyle 
(SEMENOV 1989), which is not the case of the GS2 specimen, but this feature shows some variation.

In the Balkans and the Northern peri-Pontic region this species is known from several early to middle Turolian localities, such as Pikermi (type locality) and Ravin des Zouaves (Greece), Grebeniki, Belka, Novaya Emetovka 1 \& 2 (Ukraine), Chobruchi, Taraklia and Cimișlia (Moldova) etc. (SEMENOV 1989; WERDELIN \& SOLOUNIAS 1991).

\section{Plioviverrops orbignyi (GAUDRY \& LARTET, 1856)}

Material: a fragment of a hemi-mandible with p4 of a young-adult (GPIT/MA/ 3634), probably from GS2. The distolingual cingulum is damaged (broken at the base) (Fig. 3G-H).

The p4 is longer than in Promeles palaeatticus, and the mandible depth under m1 (restored) is smaller than in 'Martes' woodwardi (see RousSIAKIS 2002). The $\mathrm{p} 2$ is too narrow for Protictitherium, with much wider and more elongated talonid, and with a much larger mesial additional cuspid (Koufos 2012). The tooth size (Table 6) is in the range of Plioviverrops orbignyi, which is a small carnivore for the middle Turolian of the Balkans; The labial and lingual cingulum in the studied specimen are stronger than in MNHN-PIK 3016a (from the type locality), but this could be related to individual variation. The anterior and posterior additional cuspids are well developed as usual in the species, as illustrated by MNHN-PIK 3047 and MNHN-PIK 3016a (another specimen, MNHN-PIK3029 , is labelled as $P$. orbignyi, but it has a less deep but thicker mandibular corpus, smaller p4 additional cuspids, a wider $\mathrm{p} 4$ talonid, its $\mathrm{m} 1$ has smaller metaconid and less obliquely positioned protoconid and the c-p1 diastema is shorter; these differences most probably indicate the appurtenance to another taxon).

Family Hyaenidae GRAY, 1821

Subfamily Hyaeninae (GRAY, 1821) MIVART, 1882

Tribe Hyaenotheriini SEMENOV, 1989 
?Hyaenotherium magnum SEMENOV, 1989

Material: left hemimandible, GS2-3154; proximal part of ulna, radius (fragmented in two parts), distal humerus from the same individual, GS8-2674.

The mandibular corpus is rather robust. The mental portion is destroyed (and the canine is separately preserved), but it is clear that the labial symphyseal edge was not smoothly rounded, but high and relatively straight. The most ventral point of the symphysis is clearly visible on the ventral border of the lateral surface of the mandibular corpus. The rostral portion of the lower contour of the mandible body is concave; the depth of the mandibular corpus under $\mathrm{p} 3$ is slightly smaller than under $\mathrm{p} 2$. The $\mathrm{m} 1$ talonid length is about $27 \%$ of the tooth length and its width - about $37 \%$ of the tooth length (the talonid is strongly worn and the height of the hypoconid cannot be estimated). All these features reveal a hyaenotheriin sensu SEMENOV $(1989 ; 2008)$. The mandible shape is different from that of Miohyaenotherium in which the ventral border of the mandibular corpus is regularly convex (SEMENOV 1989). Measurements are similar to Hyaenotherium (SEMENOv, 1989: tab. 7,9) (close to H. magnum but the appurtenance to $H$. wongii is not excluded ) and smaller than in Hyaenictitherium (Table 7, Fig. 3F). Hyaenotherium magnum is known from early to middle Turolian localities of the northern peri-Pontic region and Iran, such as Maragha (Iran), Cherevichnoe (Ukraine) and Tudorovo (Moldova).

The long bones from GS8 are too long and slender for an ictitheriin (much longer than in $I$. viverrinum) and indicate a hyaenotheriin (max. TD of humerus $=33.6$; max. APD of the olecranon of ulna $=26.7$; radius: $\mathrm{L}=18.2$, $\mathrm{TD}$ prox. $=25.8$, $\mathrm{TD}$ dist. $=18.8$ ). The size of the preserved radius matches that of H. magnum (SEMENOV 1989; 2008) and the comparison with recent dogs, wolfs and jackals indicate a body mass of about $20 \mathrm{~kg}$.

Tribe Hyaenini GRAY, 1821 
Adcrocuta eximia (ROTH \& WAGNER, 1854)

Material: right maxillary fragment with P2-M1, GS2-3158 (Fig. 3C); M1, GS2-3308 (L = 6.6 mm , $\mathrm{W}=15 \mathrm{~mm}$ ); left upper I3, GS2-3309 (L=13.6 mm, W = $11 \mathrm{~mm})$; GS2-3158, GS2-3308, and GS23309 are probably from the same ind.); m1, GS2-3158; juvenile left hemimandible, GS7-2642; fragment of a left semimandible (ramus missing), GS3-2656.

On GS7-2642, dp1 and dp3-4 are preserved. The dp1 is small and unicuspidate. The dp3 has a high, large, and strongly dominating main cusp, and a well-developed additional posterior cuspid. The dp4 has a high protoconid and an elongated trigonid; a thin cingulum is visible on the labial surface. It seems that there is no metaconid (this cuspid is missing in two out of eight specimens from Grebeniki and Chobruchi: BARYSHNIKOV \& AVERIANOV (1995). The talonid is well developed, but relatively narrow. Its surface is damaged, but the metaconid is probably higher than the hypoconid, as described in BARYSHNIKOV \& AVERIANOV (1995). The mandibular corpus is massive, as in adult Adcrocuta. The length of dp3 (13.5) is within the range (12.6 - 14.3) of the mixed sample from the Turolian of Grebeniki and Chobruchi. The length of dp4 (18.2) is also within the range of the northern peri-Pontic area (17.5 - 20.3) (BARYSHNIKOV \& AVERIANOV 1995; KOUFOS 2006). The teeth of the mandibular fragment GS3-2656 are destroyed. The mandibular body is deep (depth under $\mathrm{c}=\mathrm{ca} .46 \mathrm{~mm}$ ) and the symphysis rather vertical.

The best material is from GS2, especially the mentioned maxillary fragment (Fig. 3a \& 3b) and the lower carnassial tooth. Their measurements are (length $\mathrm{x}$ width) : GS2-3158: P4: 36.9 x 19; P3: 21.8 x 16.3; P2: 17 x $11.6 \mathrm{~mm}$. The upper anterior premolars have plesiomorphic characters: $\mathrm{P} 4$ is small. P3 is piriform, with relatively narrow distal part. P2 is especially narrow (Fig. 3C), with welldeveloped anterior and posterior additional cusps and with pronounced concavity of the lingual contour (see SPASSOV et al. 2018). On the other hand the lower carnassial tooth GS2-3158 is large (L $=30.2$ ), larger than it is in general in the lower Turolian (mean values after SPASSOV et al. 2018: 27.5; $\mathrm{n}=18$ ) and similar to the middle Turolian populations of the Balkans (mean values 29.3: 
SPASSOV et al. 2018). The cuspids of the $\mathrm{m} 1$ talonid are of similar size (rather equally developed), which is closer to the evolutionary stage of Kalimantsi and Pikermi (middle Turolian) than to the stage of Hadjidimovo (early Turolian). All these features have biochronological implications (see below).

Family Felidae FISCHER, 1817

Machairodontinae GILL, 1872

Metailurus major ZDANSKY, 1924

A fragment of a right mandible with $\mathrm{p} 3-\mathrm{m} 1$ (the distal part of $\mathrm{m} 1$ is missing, the anterior end of $\mathrm{p} 4$ is destroyed), GS10-3511 (Fig. 4A) bears high crowned teeth and a reduced p3 and shows felid features. The mandibular body under 44 is relatively deep. The teeth lack crenulations. There is no anterior additional cuspid on $\mathrm{p} 3$. The mandible fragment displays the features of the primitive machairodontine Metailurus major. The size comparison shows significantly larger dimensions than Yoshi Spassov and Geraads, 2015 and metrical similarity with the known specimens of the M. major from the Balkans and China (YU 2014; SPASSOV \& GERAADS 2015) (Table 8)

Paramachaerodus orientalis (KITTL, 1887)

Material: left hemimandible (GS2-3157; Fig. 4D-E) with c, p3 and m1; the mandibular ramus is missing.

The rostral surface of the symphysis is rather vertical, with incipient mandibular flange and moderately marked mental crest on its antero-lateral margin (as usual for the genus, SALESA et al. 2010; LI \& SPASSOV 2017). Only one mental foramen is present, positioned slightly anteriorly to $\mathrm{p} 3$. The canine is slightly compressed, with a flat lingual surface. The distal ridge is better expressed. Crenulations cannot be seen, perhaps because of the rather strong wear of the tooth. The p3 crown is elongated distally, it 
has no mesial additional cuspid and it is wider distally. Crenulations are observed on its mesial edge and weakly on $\mathrm{m} 1$. The lower carnassial is elongated, the protoconid is significantly longer than the paraconid. The talonid is well developed (Fig. 4D-E).

The Gorna Sushitsa mandible demonstrates a slightly more gracile mandible than $P$. orientalis from Pikermi, but slightly larger teeth. In tooth size it is closer to P. transasiaticus from Hezheng (China) and Hadjidimovo (second half of the early Turolian of Bulgaria: LI \& SPASSOV 2017) (Tables 9, 10). The main difference from the latter species is the $\mathrm{m} 1$ morphology and proportions: the GS2 tooth is higher and shorter. The talonid and the metaconid are not as clearly separated as they are in Paramachaerodus transasiaticus. The talonid is also significantly shorter than the talonid-metaconid complex of $P$. transasiaticus. On the other hand the talonid is longer, higher, and better separated from the distal edge of the protoconid by a horizontal groove than in Paramachaerodus orientalis from Pikermi (Fig. 4F-H). The mandible from Gorna Sushitsa 2 shows differences from P. orientalis from Pikermi, but its features are much closer to it than to $P$. transasiaticus. We could characterize the specimen as a less evolved stage of the evolution of the former species with less reduced talonidmetaconid complex.

Machairodus aff. giganteus WAGNER, 1858

(about the taxonomy of the middle Turolian Machairodus s. lato see : SPASSOV et al. 2018, p.21, p. 26).

It is represented by a heavily worn (especially its lingual surface) DP3 from GS7 (GPIT/MA/12411; Fig. 4B-C), with a length of $24 \mathrm{~mm}$. There are no visible crenulations, which could be related to the strong wear, visible on all cusps of the tooth. The metacone-metastyle blade is short, slightly shorter than the paracone, which is the larger cusp of the tooth. The parastyle is strongly affected by the wear. It is well separated from the paracone by a large and very deep valley. A small cusp (also affected by the wear) is visible slightly lingually to the mesial portion of the base of the paracone. 
The lingual root is positioned rather distally (near the middle of the tooth), under the mesial portion of the paracone. It is small and partially preserved. The anterior root is opened at its tip, the broken lingual and posterior roots show a largely hollow interior. A smooth but marked cingulum is visible at the labial surface of the crown base. Identification of a single deciduous tooth is difficult, but it probably belongs to $M$. giganteus.

\section{Order Proboscidea ILLIGER, 1811}

Family Deinotheriidae BONAPARTE, 1841

\section{Deinotherium gigantissimum STEFANESCU, 1892}

GS9-3257, right upper DP2 (Fig. 3A-B), GS9. Except for some damage on the lingual side, the specimen is well preserved. Crown enamel is abnormally developed on the labial side, expanding well beyond the cervical line and covering the preserved part of the roots. Proto- and paracone are connected by a transverse ridge forming the protoloph, the ectoloph is uninterrupted. L: $47.5, \mathrm{~W}$ : 37.5.

Metrically, the Gorna Sushitsa DP2 (Fig. 5) matches material referred by GAREVSKI \& MARKOV (2011) to Deinotherium gigantissimum, Europe's largest and latest deinothere. For the same species, the older available name D. proavum (EICHWALD 1831) has been used by e.g. CODREA (1994), GASPARIK (2001) and, most recently, PICKFORD \& POURABRISHAMI (2013). Considering the unknown present whereabouts of $D$. proavum's holotype, however, replacing the name $D$. gigantissimum with $D$. proavum might be somewhat unpractical for the time being. The species is typically Turolian, possibly occurring in the late Vallesian of Asia Minor (see GAREVSKI \& MARKOV 2011, and references therein).

Proboscidea indet.

Unidentifiable postcranials have been found at GS8 and GS 4. 


\section{Order Artiodactyla}

Family Suidae GRAY, 1821

\section{cf. Propotamochoerus sp.}

Suids are rare and cannot definitely be identified to species, but it is likely that they belong to the most common forms of the Eastern Mediterranean Upper Miocene. GS8-2691 is a mandible fragment with two contiguous premolars (Fig. 3b G-H); the first one is long and bi-rooted and slightly simpler than the second one, suggesting that they are $\mathrm{p} 2$ and $\mathrm{p} 3$ rather than $\mathrm{p} 1-\mathrm{p} 2$, but in this case they are too small ( $\mathrm{L}$ max. p3 $=13.8$; W p3 $=8.1$ ) to belong to the next species. We tentatively ascribe this fragment to Propotamochoerus, a genus present, but rare, in several localities of Greece, Republic of Macedonia (FYROM) and Bulgaria (GERAADS \& SPASSOV 2008).

Microstonyx erymanthius ROTH \& WAGNER, 1854

GS8-2684 is a maxillary fragment with DP3-M1, whose size matches that of this very common species. GS2-8288a \& b (Fig 3b I) are fragments of left and right hemimandibles from the same individual, both with $\mathrm{m} 3$ and distal parts of $\mathrm{m} 2$ ( $\mathrm{m} 3$ is of medium size: $\mathrm{L} x \mathrm{~W}=42.6 \mathrm{x} 21.6$ ). Also from GS2 (from the coll. of the UT(DG)) is a Mc IV similar in size $(\mathrm{L}=99.6$; prox. $\mathrm{W}=30$ ) to a specimen from Akkaşdağ (Liu et al., 2005). Some separate upper teeth of the same individual from GS10-3509 also belong to a medium-size Microstonyx (M3 L x W $=42.4$ x 27.6; Fig. 3b F). There is also a distal fragment of metacarpal from GS4.

Family Giraffidae GRAY, 1821

Palaeotragus cf. rouenii GAUDRY, 1861 
GS8-2630 is a distal humerus very similar in its dimensions (distal width $=76.5$; $\min$. AP diameter $=$ 38) to P. rouenii from Pikermi and many other localities (GERAADS et al. 2011). GS8-2846 is a maxilla fragment with DP2-DP4 with the size of this species.

The dimensions of a distal tibia GS8-2620 (APD $=40.6 ; \mathrm{TD}=51)$ are comparable to a small $P$. rouenii (see GERAADS 1974).

\section{cf. Bohlinia attica (GAUDRY \& LARTET, 1856)}

A few limb-bones are larger than those of the small $P$. rouenii, but smaller than those of the next species. They include: GS3-2661, a distal humerus (TD dist. = 100); GS3-2574, a metatarsal diaphysis $(\mathrm{TD}=$ c. 48); GS3-2581, a metapodial trochlea; and GS3-3161, an astragalus (medial height $=86 \mathrm{~mm}$, distal $\mathrm{W}=64 \mathrm{~mm}$ ). The metatarsal diaphysis shows that the bone was long and slender, as in Bohlinia, whose proportions were similar to those of the modern giraffe, and we tentatively assign all these remains to this taxon. GPIT 3676 (GS7) is an incomplete metatarsal whose distal end is missing; its estimated reconstructed length is about $700 \mathrm{~mm}$. (TD prox. > $66 \mathrm{~mm}$; APD prox. $=67 ? \mathrm{~mm}$; min. TD shaft $46 / 47 \mathrm{~mm}$ ).

\section{Helladotherium sp.}

GS?-2568 is a fragment of distal humerus of very large size; GS4-3513 is a fragment of a large upper premolar. BAKALOV \& NIKOLOV (1963, pl.30, fig.5) illustrated a large upper molar. These remains are insufficient for a generic attribution, but we tentatively assign them to Helladotherium. Some very large bones from GS2, metacarpus and phalanx I (stored in the coll. of the UT(DG), unnumbered), and a distal humerus GS2-916 (from the same individual?), must represent Helladotherium, being more massive and a trifle larger than in Samotherium major (MC: L max. = 440mm, TD dist $=108.7$, TD prox. $=112$, TD shaft min. $=64$; Phal. I: $\mathrm{L}=119$, DT prox. $\max .=$ 
51.4, TD prox. $=46$, TD dist. 54; distal humerus GS2-3516: $\mathrm{TD}$ of trochlea $=141$; $\mathrm{TD}$ max. of the distal end $=163$ ).

Family Bovidae GRAY, 1821

Tribe Boselaphini KNOTTNERUS-MEYER, 1907

Tribe Boselaphini KNOTTNERUS-MEYER, 1907

The revision of Tragoportax Pilgrim (SPASSOV \& GERAADS 2004) led to the distinction of two different boselaphin taxa in the late Miocene of the Balkan, Tragoportax Pilgrim and Miotragocerus (Pikermicerus) Kretzoi. The latter genus was recently regarded by the same authors as a separate genus, Pikermicerus Kretzoi, represented in the Turolian fauna by P. gaudryi (SPASSOV et al. 2018). This latter taxon was called instead Miotragocerus valenciennesi (GAUDRY, 1861) (= Tragocerus valenciennesi,$=$ Graecoryx valenciennesi) by KostOPOULOS $(2005 ; 2009)$, although this name is based upon a juvenile animal, to which SPASSOV and GERAADS (2004) proposed to restrict this name. Tragoportax was defined (SPASSOV \& GERAADS 2004) as more derived than M. (Pikermicerus), characterized mostly by a well bordered and defined, depressed postcornual frontoparietal area, by a clear longitudinal groove on the basioccipital as well as by the triangular cross section of the male horn-cores, with marked posterolateral keel and weakly expressed steps of the anterior keel. The type of Miotragocerus monacensis from Oberföhring (at the middle/late Miocene boundary) displays a frontoparietal region similar to that of Tragoportax (well shown in Fuss et al., 2015). The morphology is unclear in the type of Dystychoceras pannoniae Kretzoi (=? Miotragocerus pannoniae), while "Miotragocerus gregarious" of Zhang (2005) displays in fact all the features of Tragoportax. The morphology of the basioccipital in M. monacensis is poorly known but that of its horncores is different and plesiomorphic in comparison to Tragoportax: the anterior keel has strong steps, and the cross-section of the horncores is oval (not triangular as in Tragoportax). The deep, well-delimited depression of the frontoparietal area in M. monacensis suggests close relationship 
between Miotragocerus and Tragoportax. The latter, showing apomorphies and being geologically younger in age, may originate from the former. On the other hand the similarities in the frontoparietal area of Tragoportax and M. monacensis, type species of Miotragocerus STROMER, 1928, which contrast with the morphology seen in Pikermicerus, support (besides the massive, short horn cores) the generic separation of Pikermicerus from Miotragocerus and confirms that Pikermicerus gaudryi KRETZOI, 1941, not M. valenciennesi, is the valid name of the small Boselaphini from Pikermi.

Tragoportax amalthea (ROTH \& WAGNER, 1854) and Tragoportax cf. amalthea. Tragoportax (Fig. 6a E-H, 6b A-B, 7F ) is abundant in the various localities of Gorna Sushitsa: skull GS8-2638; maxillae GS2-2806, GS3-2901, GS3-2831, GS3-3147, GPIT 03557 (GS12); mandibles GS3-2836 GS8-2594 and GS8-2647 (Fig. 7F) of the right size (see molar row length) for the genus (Tables 11, 12); basioccipital bone with the morphology for the genus, width over the posterior tuberosities $=38.2$. Several postcranials could also be assigned to Tragoportax (see below).

The teeth of GS3-2901 (right and left P2-M2 rows) are in bad condition, but the premolars are of the right shape and size for the genus (L P2-P3 $\max .=47.8, \mathrm{P} 2$ is short, shorter than P3).

It should be noted that in several specimens (GS8-2638, GS3-2831 and especially GS2-2806), P2 is elongated, and can be longer than P3 because of the long preprotocrista-parastyle area, having with this some similarity with Pikermicerus gaudryi. This mesial part of P2 is lower than the main occlusal surface and is affected by wear in old individuals only. In this feature, the specimens from Gorna Sushitsa resemble T. amalthea from Pikermi (Fig. 6b E-F) and differ from T. rugosifrons from Hadjidimovo (Fig. 6b A-B) (see also SPASSOV \& GERAADS 2004). This feature could reflect be a specific environmental adaptation of $T$. amalthea (see below).

The almost complete skull GS8-2638 is the most informative Tragoportax fossil (Table 13, Fig. 6EH). It is the only specimen that can be identified to species level. The skull is slightly crushed 
dorsoventrally, increasing the angle between the neurocranial and the visceral part of the skull, the inclination of the horn-cores, and the rostro-caudal diameter of the orbits. The ante-orbital fossa is long rostro-caudally and deep. The horn-cores are long, with a great antero-posterior diameter, and are slightly curved backwards (the caudal surface is moderately concave) and with a weak torsion. The anterior keel is strong, with rugosities extending onto the frontal in its basal part, but no steps; the shape of the keel near the tips is unclear because of distortion. The horn-core basal section is triangular, the posterolateral keel is well-marked. The intercornual plateau is narrow and V-shaped, as the horn-cores are inserted close to each other. The postcornual frontoparietal area is well delimited, depressed. The basioccipital shows a clear longitudinal groove between the anterior and the posterior tuberosities. The dorsal part of the occipital is broad. The choanae open well behind M3. The small intercornual distance ( $\mathrm{V}$-shaped contact of the horn-core bases in frontal view), the curved posterior border of horn-cores, the massive horn-core bases with well-developed rugosities, are differences from T. rugosifrons. In general shape GS8-2638 shows similarities with the Tragoportax from the early Turolian locality of Nikiti2 (Kostopoulos 2016, fig. 4), described as T. amalthea, and in any case close to the ancestry of this species. The skull from GS8 closely resemble $T$. amalthea from the type locality Pikermi and from Halmyropotamos (SPASSOV \& GERAADS 2004), and must be assigned to this species. The remaining, less complete, Tragoportax material from Gorna Sushitsa probably belongs to this species as well, especially because of the upper premolar morphology.

\section{Pikermicerus gaudryi KRETZOI, 1941}

The mandibles GS8-2663 and GS8-2659 (Table 12) have the size of Pikermicerus gaudryi and must represent this taxon. The mandible GPIT-3668 from GS7 with similar dimensions and an elongated premolar row probably represents the same taxon. 
Several postcranials from GS3, GS7 and GS8 must belong to Tragoportax or Pikermicerus, but the generic distinction is not easy. Incomplete tibiae GS8-2620 (male: TD dist. $=49 \mathrm{~mm}$ ), GS3-2864 (male? TD prox. $\sim 70$ ) and 2865 (female? : TD dist. $=39 \mathrm{~mm}$ ) as well as the phalanxes associated with the latter two tibiae must be referred to Tragoportax. The calcanei GS3- 2855 (total length = 106.2mm), GS3-2864 (total length = 103.4), GS8-3671 $($ a fragment $)$, astragali GS3-2868 $($ TD dist. $=$ 31), GS7-2854 (TD dist. = 32), and GS8-2670 ( $\mathrm{L} \times \mathrm{TD}$ dist. $=51.7 \times 29.8)$, as well as phalanxes GS8-3510a-c (phal.I: L x TD prox. = 54.6 x 22; phal.II: 36 x 29=6; phal.III: 48.3 x 17) could probably be referred to this taxon as well.

The metatarsal GS3-2865 (TD prox. x APD prox. $=32.3 \times 36$; TD dist. X APD dist. $=35 \mathrm{x}-$ ) could be from a female Tragoportax or from a large Pikermicerus; the smaller damaged metatarsal distal fragment GS8-2902 as well as the phalanges I-III (GS8-2903, 2904, 2905) from the same individual $(\mathrm{L}$ of phal.I $=49 \mathrm{~mm}$; $\mathrm{L}$ of phal.II $=33.2 ; \mathrm{L}$ of phal.III $=40)$ probably belong to Pikermicerus.

\section{Palaeoryx sp.}

GS7-2832 is the palate of a large antelope with erupting premolars and third molars (left DP4 not shed). GS7-2901 is a palate with complete but worn tooth-rows. Their large size alone (Table 14) suggests identification as Palaeoryx rather than as a member of the slightly smaller Protoryx / Skoufotragus group, but this distinction is only partly supported by their morphological characters. The labial walls of the molars of GS7-2832 are distinctly less flattened than in this group, but this is much less clear of GS7-2901, perhaps because they are more worn. Still, it is more parsimonious to assign both specimens to the same taxon. Although the premolar/molar index falls within the range of Palaeoryx (Table 14), it is smaller in both specimens than in all Palaeoryx that we have measured. The metric and morphological distinction from Tragoportax are not easy either, as noted by GENTRY (1971); however, their size, slightly larger than that of the Tragoportax specimens from GS, the broad palate, the massive pillars of the lateral walls, the lack of fusion between the distal arm of the 
protocone and the mesial arm of the hypocone, the strong mesostyle, and the relatively short premolars, are all unlike this genus. A partial frontlet GS4-3517 of large size (width over pedicles = 2x68) with much weathered horn-cores must also belong to Palaeoryx (Fig. 7A) group. The frontoparietal profile is but slightly curved, less so than in members of the Protoryx group. The horncores are almost parallel (divergence angle $=$ c. $\left.10^{\circ}\right)$, strongly compressed $(70$ x c. 45$)$, rather strongly curved backwards, probably short, with a large basal sinus, no keel or torsion, with a maximum transverse diameter located distinctly anteriorly. The short horn-cores and their strong compression are unlike known species of Palaeoryx, and this specimen might deserve a new species name, but we refrain from erecting it because of its poor preservation.

Not to mention the skull differences, the large metric variation of specimens from various sites assigned to Palaeoryx (Table 14) suggests that some of them may have been incorrectly identified, or that more than a single species is present, the two hypotheses being not mutually exclusive. Indeed, Kostopoulos $(2005,2009)$ recognized the validity of the species erected by Schlosser at Samos, P. majori, which has (among other characters) shorter molar rows than the type species $P$. pallasi. If this distinction is valid, there is no doubt that GS7-2901 is more like the latter species, because of its small $\mathrm{Pm} / \mathrm{M}$ index. This brings it closer to the somewhat mysterious large form called Samokeros minotaurus SOLOUNIAS, 1981. However, if the identifications of specimens assigned to this form are correct, its premolars are smaller still, as noted by KOSTOPOULOS \& BERNOR (2011), and the labial styles and pillars of the upper teeth are much less protruding than in GS7-2832. Therefore, we tentatively assign the Gorna Sushitsa specimens to Palaeoryx, bearing in mind that they may be insufficient for formal identification.

cf. Skoufotragus laticeps (Andree, 1926)

A braincase with relatively complete horn-cores from GS2 (Fig. 6b G-H), now in Tübingen (GPIT/MA/03599), is too small to be of the same species as the above-mentioned teeth. The horn 
cores are very long, moderately divergent at the base but increasingly so upwards, moderately curved backwards, and uprightly inserted (angle between their posterior border and fronto-parietal profile in lateral view c. $85^{\circ}$ ). It is definitely a member of the group that includes mostly Pachytragus and Protoryx, to which Kostopoulos (2009) added Skoufotragus, but is somewhat peculiar in its relatively small size, very long horn-cores with strong divergence (perhaps increased by distortion ?), and poor horn core compression $(\mathrm{APD}=52 ; \mathrm{TD}=47)$.

\section{Palaeoreas lindermayeri (WAGNER, 1848)}

This is the most common medium-sized bovid at Gorna Sushitsa, but all the material (listed in Tables 15 and 16) is from GS3, GS7, GS8 and GS12 (Fig. 7D). The stout, tightly spiraled horn-cores are similar to those of the nearby sites of Kalimantsi, Hadjidimovo (GERAADS et al. 2003) and perhaps Kocherinovo (HRISTOVA et al. 2013), and to those of the type-locality Pikermi.

Dental remains are assigned to $P$. lindermayeri on the basis of their size and morphological characters, listed by GENTRY (1971) and GERAADS et al. (2003). A homogeneous group of medium size, which is by far the most common one, can therefore unambiguously be assigned to this taxon (this is the opportunity to correct an unfortunate mistake: although their numbers and scale bar are correct, the tooth-rows from Hadjidimovo illustrated by GERAADS et al., 2003, fig. 2, as of

\section{Palaeoreas lindermayeri are in fact of Tragoportax).}

Upper premolars are small; no P2 is preserved at GS; P3 about as long as P4 but narrower and its lingual crescent is distinctly bilobed, P4 is V-shaped rather than U-shaped in occlusal view, i.e., it is much shorter lingually than bucally, as at Hadjidimovo (and in sharp contrast to GERAADS et al., 2003, fig. 2 !). The molars have minute entostyles and moderate labial ribs and styles.

The characters of the lower teeth mostly agree with those of GENTRY (1971) and GERAADS et al. (2003): the premolars are large relative to the molars, $\mathrm{p} 3$ is long as $\mathrm{p} 4, \mathrm{p} 4$ has a transverse metaconid that tends to close the lingual valley, the molars have ectostylids and incipient goat folds However, as 
at Hadjidimovo, Kalimantsi, and Vathylakkos 1 (BouVRaIn 2001) the labial groove of p4 may be deep.

The relative abundance of Palaeoreas remains at Gorna Sushitsa allows some metric comparisons with other sites (Tables 15, 16). The horn-cores are clearly closer in size to those of Pikermi and Kalimantsi than to those of Hadjidimovo, but the reverse is true of the lower dental series, which are about as large as those from Hadjidimovo and larger than those from Pikermi, those from Kocherinovo being intermediate (HRISTOVA et al. 2013).

\section{Prostrepsiceros rotundicornis (WEITHOFER, 1888)}

GS3-2830 is a rather well-preserved frontlet with nearly complete horn-cores (Fig. 7B-C). The skull roof is somewhat compressed dorsoventrally, so that any frontoparietal angle or supra-orbital fossa surrounding the supra-orbital foramina may have been flattened. The latter open close to the horncores, not very far apart. The mid-frontal suture is slightly raised, and complicated. The horn-cores are regularly twisted in an open spiral, quite different from the tight torsion of Palaeoreas. Their section is almost round, except for a flattened posterior part that creates a posterolateral change of curvature that increases upwards to form an incipient keel.

All these features are virtually identical with those of the Pikermi variety (see GENTRY 1971) of P. rotundicornis, first figured by WEITHOFER (1888, pl. 18, figs. 3-5), one of the specimens upon which he based the species, and which we have examined in the University of Wien. It is also very similar to horn-cores and frontlets from Pikermi in MNHN and NHMUK, to the frontlet FM-2739 from Strumyani (GERAADS et al. 2011), but does not show the keels and grooves that KosTOPOULOS (2005) described at Akkaşdağı. The horn-cores from Perivolaki (KostoPOULOs 2006) also look somewhat different in their elliptical cross-section, and they also bear grooves or weak keels. Still, in the course of its horn-cores, the Gorna Sushitsa form is more similar to them than to what GENTRY (1971) called "A second variety from Samos and Maragha", which was distinguished as Pr. fraasi by 
AndREE (1926), a name accepted by Kostopoulos (2005, 2006, 2009) and Kostopoulos \& BERNOR (2011). Prostrepsiceros fraasi has horn-cores that are more strongly divergent at some distance above the base (ANDREE 1926, pl. 11, fig. 4; SOLOUNIAS 1981, fig. 43; MECQUENEM 1925, pl. 7, fig. 1) but the Perivolaki form looks intermediate in this regard (Kostopoulos 2006, pl. 2). The mandible GS8-2622 (Fig. 6F) clearly differs from those assigned to Palaeoreas in its longer premolar row, and p4 with a much broader central lingual valley and paraconid indistinct from preparaconid. Its premolars are slightly longer than in Palaeoreas but the molars shorter, so that the $\mathrm{Pm} / \mathrm{M}$ index is distinctly higher (Table 15). It is closest to $P$. rotundicornis from Akkaşdağ1 (Kostopoulos 2006, table 9), whereas this index is lower in all other populations of this species. Prostrepsiceros is a rare form in Bulgaria, and all specimens can probably be attributed to Pr. rotundicornis: this species is present at Strumyani (GERAADS et al. 2011), and probably also at Kalimantsi, where it is rare. Remarkably, it is absent from the rich site of Hadjidimovo. It is also rare in the sites of the Axios Valley in Northern Greece, where its only definite occurrence seems to be at the locality Ravin des Zouaves 5 (BouvRAIN 1982).

\section{Gazella cf. capricornis (WAGNER, 1848)}

Gazella remains (Fig 7H) are relatively abundant, but most of them are incomplete and species identifications are difficult. Some horn-cores are moderately compressed and rather strongly curved backwards; in their size, curvature, and degree of compression, they fit G. capricornis, a common species found, among others sites, at Pikermi, Samos, Akkaşdağı, and Maragha (BoUVRAIN 1996, 2001; Kostopoulos \& Koufos 1999; Kostopoulos 2005, 2009). However, identification of isolated gazelle horn-cores is risky, so that the present one is tentative. GS7-2853 is perhaps of the same individual as GS7-2852. Its measurements are:

occlusal length P2-P4 = 22.3; occlusal length P2-M3 = 54.5 


\section{? Gazella sp. B}

The horn-cores GS8-2629 are very large (Table 16), larger and less curved than those of the Gazella cf. capricornis, with an almost straight distal portion; the lateral side of the pedicle is long. GS8-2678 and GS2-3159 are probably of the same species. In their large size, these specimens clearly differ from the common Eastern Mediterranean late Miocene gazelles, they reach the size of the largest G. mytilinii from Samos (Kostopoulos 2009), but here this large size is clearly not the extreme of a range. It is best not to attempt species identification.

Oioceros rothi (WAGNER, 1857)

GS3-2829 is a frontlet with most of the horn-cores, which are strongly twisted in an homonymous direction on their almost straight axis (Fig. 7I). At the base, the section is somewhat bean-shaped, with a posterolateral depression underlined by a lateral ridge that becomes better indicated upwards, almost ending as a keel.

GS8-2906 (Fig. 7E) is a mandible with complete cheek-tooth row. The premolars are long with widely open lingual valleys. The central valleys have almost completely vanished on the moderately worn molars, as in other antilopins. Given the presence of undoubted Oioceros horn-cores, it is more parsimonious to ascribe this mandible to the same genus.

Kostopoulos (2014) revised the systematics of Eastern Mediterranean antelopes with homonymous horn-cores, and separated Oioceros atropatenes, mostly known from Maragha, from $O$. rothi that has a wider geographic range, and has larger horn-cores (GERAADS 2013, fig. 5) with better indicated grooves and ridges. The Gorna Sushitsa frontlet clearly falls in the latter species.

Family Equidae Gray, 1821 
The hipparion fossils (Fig. 6A-D; Tables 17-19) from Gorna Sushitsa localities are not so abundant as in several other Bulgarian late Miocene localities, and most of them are badly preserved. Still, the hipparions are more widely distributed in the GS localities than the other groups of large Mammals. All equid measurements follow EISENMANN et al. 1988.

Cremohipparion mediterraneum (ROTH \& WAGNER, 1855)

There are only three cranial fragments, from GS3. The first (GS3-3144) is badly preserved, with only the cheek area and the preorbital fossa area available. The fragment is of a medium sized hipparion: the premolars are $83.4 \mathrm{~mm}$ long, the distance from the anterior rim of the orbit to $\mathrm{P} 2$ is $173.3 \mathrm{~mm}$. The preorbital fossa is subtriangular, dorsoventrally compressed. The preorbital bar is short (19 $\mathrm{mm})$; the preorbital fossa is moderately deep, with shallow posterior pocket, and high above the facial crest (approximately $35 \mathrm{~mm}$ ). The dorsal and anterior borders of the fossa are not prominent. The area of the nasal slit and the subnasal fossa are damaged, but there was probably no canine fossa. The premolars are in early stage of wear and their enamel pattern is not visible yet. The protocone is elongated, with a spur on P2. The pli caballin is single.

The second cranial fragment (GS3-2696; Fig. 6A-B, Table 17) is also in bad condition, preserving only the maxilla above the tooth row and part of the right orbit. It belongs to a medium sized hipparion, with a molar tooth row length of $61 \mathrm{~mm}$, and a distance from orbit to P2 of $158 \mathrm{~mm}$. The facial crest ends above the posterior half of P3, the choanae ends at the level of M2-M3. The orbit is about $5 \mathrm{~mm}$ behind M3. The preorbital bar is $25 \mathrm{~mm}$ wide. The preorbital fossa is subtriangular, of medium depth, with shallow pocketing and is anteroventrally oriented. The cranium is dorsoventrally crushed, and the anterior border of the fossa is not well preserved. The tooth row is short (130 mm), mostly because of its very advanced stage of wear - P2 and the anterior half of P3 lost all enamel features due to abrasion, . The protocone is connected with the hypoloph on P3 and M1, and is close to connection on M2. On P4 and M3 it is still isolated, elongated and labially flattened. The pli 
caballin is vestigial, with one or two folds. The hypocone is rounded, with shallow hypoconal groove, and vestigial lingual groove on M3. The enamel plication is low -9-13 plis. There is a DP1. The cranial fragment GS8-2695 (Fig. 6C-D, Table 17) preserves only the anterior part, from the incisors to the level of M1. There is well developed buccinator fossa, and a subnasal one. The nasal slit is retracted to the anterior end of P2. The only available measurements (see EISENMANN et al. 1988) are $\mathrm{m} 1=113 \mathrm{~mm}, \mathrm{~m} 7=67.3 \mathrm{~mm}, \mathrm{~m} 14=41 \mathrm{~mm}$ and $\mathrm{m} 15=58.6 \mathrm{~mm}$. The teeth are heavily worn; the height of P2 is about $7 \mathrm{~mm}$, which could explain the short premolar length. Despite the bad preservation of the skulls, the short preorbital bar, the shape of the fossa and its shallow pocketing are features similar to Cremohipparion group and the greatest similarity is with $C$. mediterraneum (KoufOS 1987a). The long premolar row, the shape and size of the fossa, as well as the large distance orbit - P2 differ from C. moldavicum (GROMOVA 1952). The moderately deep preorbital fossa and the shallow pocketing distinguish the skulls from C. proboscideum (KoufOS 1987b; SPASSOV et al. 2018).

The cranial fragment from GS9 (GPIT/MA/3661) is almost identical to GS8-2695, but only the ventral bones with the teeth are preserved. The presence of only three cranial fragments of adult individuals of $C$. mediterraneum do not allow to investigate the intraspecific variability of the species.

\section{Hippotherium brachypus (HENSEL, 1862)}

The more significant remains of $H$. brachypus are extremely scarce; GS4-3307: The specimen is of a juvenile individual - M2 is still in the alveolus, only its tips are visible; there are only germs of the premolars and M3 (Table 17). The cranium is highly fragmented, but some of the taxonomically valuable features are preserved: it is a medium to large sized hipparion (the distance orbit-P2 at the alveolar rim is approximately $170 \mathrm{~mm}$ ), the preorbital bar is $51 \mathrm{~mm}$, the fossa is moderately deep (about $18 \mathrm{~mm}$ ), with shallow pocket; the deciduous premolar length is about $87 \mathrm{~mm}$ (measured at the 
alveoli). These features show greatest similarity with Hippotherium, the shallow pocketed fossa relates it to H. brachypus (BERNOR et al. 1997; KoufOS 1987a).

There is a mandible fragment GS 7-3137 that could be assigned to this species. Its dimensions are within the range of variation of $H$. brachypus and $C$. mediterraneum from $\mathrm{HD}$, as well as within those of some other samples of H. brachypus; the enamel patterns of the teeth (the crenulated enamel of the pre- and postflexids) and the large value of m13 clearly show its similarity with $H$. brachypus.

Postcranials (Tables 18, 19). As none of them were found associated with skulls, they are hard to identify, especially as most of them are not complete, and distorted. They can be separated in three groups:

Robust group (cf. Hippotherium brachypus (HENSEL, 1862); BERNOR et al. 1997; KoufOS 1987a, 1987b)

Here we assign the metacarpals GS2-3272 and GS2-3558 T (stored at the UT(DG), GS8-2616, GS23165A, GS8-2616 (Mc III).

Slender group (Hipparion dietrichi (WEHRLI, 1941) or Cremohipparion mediterraneum (ROTH \& WAGNER, 1855); Koufos 1987b; Koufos \& Vlachou 2016; Vlachou \& KoufOS 2016)

GS1-2591 (Mc III), GS2-3274 (astragalus), GS2-3273 (calcaneus), GS2-3277 (Mt III), GS3-2900

(Mt III), GS4-3177 (Mt III); GS4-3256 (Mc III), GS4-3268 (Mt III), GS7-3533 (Mc III), GS8-2627

(Mt III), GS8-2632 (Mt III), GS9-2556 (Mc III)=

Two metacarpals from GS3 (GS3-2899 and GS3-3255) are incomplete, all that can be said is that they are in the range of variation of $H$. brachypus and C. mediterraneum.

Small sized group. Without cranial material it is hard to say anything more specific about the small hipparion species discovered at the localities GS3 and GS8: GS3-3139 (humerus); GS3-3264 (astragalus); GS8-2631 (Mt III). They could be referred to Cremohipparion macedonicum or C. matthewi or C. sitonis (see Koufos 1987b; KoufOS \& VlachOU 2016; VlaCHOU \& KoufOS 2016) 
Family Rhinocerotidae GRAY, 1821

\section{Chilotherium sp.}

GS4-3135 is a short and stout calcaneus; it resembles other Chilotherium (Kemiklitepe: GERAADS 1994, pl. 2, fig.3; Ch. anderssoni: RINGSTRÖM, 1924, fig. 40) in its size and proportions and distally expanded lateral astragalar facet. A short, robust Mt IV GS3 $(\mathrm{L}=$ c. 98 ; width of shaft = c. 36$)$, a pyramidal GS8-2625, a lunar GS-8-2623, and a scaphoid GS8-2624 confirm the presence of Chilotherium, but more precise identification is impossible. A very small humerus dist. GS8-2630 can probably also be referred to this genus.

\section{Acerorhinus sp.}

GS7-3142 (Fig. 9A-B) is an almost complete skull, lacking only the nasals and premaxillae; the teeth are well-preserved but much worn. It resembles the skull from Kalimantsi (GERAADS \& SPASSOV 2009 , pl.2) in its strong sagittal crest, tall triangular occipital, deep robust zygomatic arch, cheek teeth with flat labial walls, large premolars, molars with antecrochet and lingually flattened protocone. It differs from the Kalimantsi skull in being slightly longer but narrower, and in the slightly more posteriorly located cheek-teeth.

Measurements: length from orbit to nasal notch $<72$; bi-orbital width $=153$; width over post-orbital processes $=170$; length $\mathrm{P} 2-\mathrm{M} 3=233$; length from condyle to rear of M3 = 240; bi-mastoid width = 195; bi-zygomatic width $=285$.

There is no need to repeat here the discussion of this genus (GERAADS \& SPASSOV 2004). Once again, unfortunately, the skull offers no information about the presence of upper incisors, said to be lacking in this genus. Only a full study of the Chobruchi (PAVLOW 1914) and Turkish material would clarify the issue; in the meantime, we will not attempt a species identification. 
Ceratotherium neumayri (OSBORN, 1900)?

An upper series of deciduous teeth DP1-DP3 GS8-2912 (Fig. 9C) matches better Ceratotherium neumayri than Dihoplus pikermiensis, commonly found in the same bioprovince and sometimes in the same localities (GERAADS 1988). The teeth are long, the cingulum is strong, there is a closed medifossette on DP3, and the metaloph of DP2 is transversally oriented.

GS8-2837 is the posterior part of a juvenile skull that preserves very few diagnostic characters; only distorted un-erupted teeth are visible. The temporal lines remain wide apart, making identification as Acerorhinus or Chilotherium unlikely. The ventral border of the orbit is rounded, as in

Ceratotherium, in contrast to the sharper border of Dihoplus pikermiensis, and the long posttympanic process is also more like in the former taxon.

A proximal radius GS7-3138 and a proximal radius GS4-3512 $(\mathrm{TD}=110 \mathrm{~mm}$.$) are of the right size$ for this species. GS8-2589 is an unciform. GS8-2664 is a proximal Mc III, and GS8-2590 a proximal Mc IV, perhaps of the same individual. A Mc IV in UT(DG) has a length of 166.5 and a distal transverse diameter of 40.4. Other metapodials are:

Mt III GS3-2570 L = 172; prox. $\mathrm{W}=50$; midshaft $\mathrm{W}=49$; dist. articular $\mathrm{W}=46.5$. Mt II GS3-2571 (probably of the same individual) $\mathrm{L}=146$; prox. $\mathrm{W}=30$; dist. articular width $=37.2$. GS3-2572, GS8-2626, and GS8-2588 are three astragali (max. $\mathrm{W}=$ resp. 103, 97, 101; medial height $=79,80$, 78.5).

Family Chalicotheriidae GILL, 1872

Anisodon sp. ?

A juvenile maxilla with right DP2-4 and left DP3-DP4 GS10-3514 is clearly chalicotheriine (Fig. 9G). The DP3 is much smaller than DP4, and distinctly more square (less trapezoidal than at Neudorf: ZAPFE 1979). On both teeth the mesial cingulum does not reach the lingual border, the protoloph ends at the paraconule, and the distal cingulum reaches the top of the hypocone. The 
posterior arm of the metacone is less transverse than on the M3s of Chalicotherium goldfussi, but less mesio-distally oriented than in the DP3-DP4 of Anisodon grande from Neudorf (ZAPFE 1979, fig. 23). In addition, there is a distal Mc II GPIT/MAI 3626 with a distal width of 49.5 , and a mandibular fragment figured by BAKALOV \& NIKOLOV (1962, pl.16, fig.2).

Ancylotherium pentelicum (GAUDRY \& LARTET, 1856)

GS7-2584 (Fig. 9D-F; Table 20) is an almost complete Mt IV. It compares favorably with two Mt IVs from Pikermi in the MNHN, but the Mt III facet is longer in palmar direction. The Pikermi specimens differ significantly in their proportions, perhaps reflecting sexual dimorphism; the specimen from GS is closer to the shorter one.

GS7-2585 is a first phalanx and GS7-2586 is a second phalanx. BAKALOV \& NIKOLOV (1963) illustrated a maxilla with P2-M2, briefly discussed by GERAADS et al. (2006).

\section{Discussion and conclusion}

Although the existence of different fossiliferous spots must be kept in mind, we believe that the possible differences between the fossil assemblages that are sampled at each of them are in general beyond recognition, given the small size of the collection. We feel justified, therefore, to use the whole collection (with some exceptions, see below) in the following comparisons.

BIOSTRATIGRAPHIC IMPLICATIONS. In several aspects the fauna of GS, especially that of the upper levels, is close to that of Pikermi (Table 21). As a whole the composite fauna of Gorna Sushitsa demonstrates the features of the typical middle Turolian fauna of the Balkans, a rather short faunal zone (SPASSOV et al. 2018) which could coincide, according to SPASSOV et al. (2017) with the so called "Pikermian event" sensu Kostopoulos (2009). The Gorna Sushitsa fauna is characterized by typical Pikermi faunal elements and features, such as: abundance of hipparions (especially $C$. 
mediterraneum, which after the distance of the preorbital fossa from the facial crest (values above 20 mm:GS3) is close to the populations from Kalimantsi and Pikermi )); abundance of Gazella and Tragoportax Amalthea as well as of spiral-horned bovids (Palaeoreas); abundance of Mesopithecus pentelicus, very similar to the sample from the typical locality of Pikermi; Ceratotherium seems to be the more common rhino; the giraffids Palaeotragus cf. rouenii and Bohlinia attica are common. Only GS2 (and the localities stratigraphically below it) yields more archaic evolutionary stages of several mammals (Adcrocuta eximia and Paramachaerodus orientalis). Some trends in the evolution of Adcrocuta eximia teeth from the Vallesian/Turolian transition to the end of the middle Turolian are noticed by SPASSOV (in SPASSOV et al. 2018). The following trends can be indicated in relation to P2P3 (Fig. 3b): a reduction of lingual cingulum and additional cusps; a widening of the crowns of the mentioned teeth, mainly due to a widening of their distal portions: the shape of the teeth in occlusal view becomes from a kidney-like, with a strongly concave lingual surface (Hadjidimovo, Bulgaria) or a pear-like/elliptical one (Hadjidimovo) to rectangular, with a tendency to square (Pikermi, Greece). At the same time, there is a tendency to increase (as a whole) the size of carnassial teeth. The lower carnassial tooth of $A$. eximia from GS2 has a plesiomorphic, very prominent paraconid cingulum, but is apomorphic in size, larger than in the lower Turolian and similar to the middle Turolian populations of the Balkans. The large size of the $\mathrm{m} 1$ in GS2 could be related to an extreme individual variation, but it could be explained mostly by the geological age of the locality, which seems to be very close to the lower/middle Turolian boundary. The morphology of the upper premolars is more indicative and the P2-P3 features show similarity with the late Early Turolian populations as the one from Hadjidimovo (Bulgaria), which could be positioned in the second half of the early Turolian (SPASSOV et al. 2018; Li \& SPASSOV 2017). As a whole, according to one of us (N.S.), the features of A. eximia from GS2 reveal a stage more primitive than the typical one for the middle Turolian population of the Balkans (such as those from Kalimantsi, Bulgaria and Pikermi, Greece) but probably more evolved than the one from Hadjidimovo. This agrees with the 
morphological stage of the m1 of Paramachaerodus from GS2, which represents an early (prePikermi) stage of $P$. orientalis, but differs from the earlier, late early Turolian $P$. transasiaticus from Hadjidimovo. We conclude that GS2 is most probably an early Turolian locality, but very close to the early/middle Turolian transition. Its age, after the magnetostratigraphic dating (BöHME et al. 2018 ) is 7.44 Ma. According to one of us (N.S.), the differences between GS2 and the localities above it could correspond to the early/middle Turolian transition. The presence in GS2 of cf. Skoufotragus laticeps is possibly also an indication of a pre-Pikermi age of this locality. The level of the classical Pikermi site (which could be reached by the uppermost Gorna Sushitsa localities, where Mesopithecus is indiscernible from the Pikermian population) is placed at about 7.33 and the middle Turolian could finish with the faunal turnover related to the Anancus appearance in Europe, which is slightly below the Tortonian/Messinian boundary, very close to (slightly below) $7.25 \mathrm{Ma}$ (BöHME et al. 2017; SPASSOV et al. 2012; 2017). In conclusion, the fauna from the Gorna Sushitsa localities discussed here could be placed ( see BöHME et al. 2018) in a rather short interval, of about $130 \mathrm{Ka}$. Above the level of GS2, it is difficult to see changes in faunal composition or evolutionary stages, perhaps because of the small number of significant fossils/species collected from the different fossiliferous spots, but also to the short time span of the accumulation of the GS fossiliferous deposits.

PALEOECOLOGICAL IMPLICATIONS . As shown by the dominant faunal elements, the paleoenvironment of Gorna Sushitsa was favorable for grazing forms, such as Cremohipparion and Ceratotherium, and for mixed feeders and/or browsers such as Gazella, Tragoportax, Palaeoreas, Pikermicerus. All of them are found in relatively dry and open/semi-open/bushland-like landscapes, but they are accompanied by taxa related in their feeding habits and mode of life to woodlands and forest savannah habitats, such as chalicotheres, giraffids and Mesopithecus (SPASSOV 2002; MERCERON et al. 2006; GeraAdS et al. 2006; GeraAdS \& Spassov 2009; Clavel et al. 2012; 
MERCERON et al in press). A particularity of Tragoportax (which could be identified as T. amalthea) is the elongation of the mesial part of $\mathrm{P} 2$, in comparison to the form from the late middle Turolian locality of Hadjidimovo (HD), Bulgaria (see: SPASSOV \& GERAADS 2004). It could be supposed that Tragoportax from GS is more a browser than the one from HD. We find support for this assertion in the conclusions of MERCERON et al (2006), according to which Tragoportax cf. amalthea from Kalimantsi (whose chronostratigraphic range is similar to that of GS) was browser to a much greater extent than the mixed feeder T. rugosifrons from HD. In relation to this we can imagine that the landscape from the early to the middle Turolian in the area gradually evolved from a mosaic one to a more homogenous xerophytic bushland, which requires more browsing habits, in conditions of an increasing (BÖHME et al. 2017) aridification.

Aknowledgments. The main field missions in GS were realized in the frames of the joint exchange program of CNRS and the Bulgarian Academy of Sciences as well as with the support of the MNHN and NMNHS. The authors are grateful for the help in the field surveys to TZANKO TZANKOV and KRASSIMIR STOYANOV (South-Western University, Blagoevgrad) as well as to YANKO and STOYAN (Gorna Sushitsa village) for the logistic support during the excavations. Localities 11 and 12 were discovered by the team from the UT(DG) (led by MADELAINE BÖHME), which detected also several fossils during their work on the geology of Gorna Sushitsa, now stored in NMNHS and in the UT(DG). The comments of DIMITRIS KOSTOPOULOS and of an anonymous reviewer greatly improved the manuscript.

\section{REFERENCES}


Alba, D., Montoya, P., Pina, P., Rook, L., Abella, J., Morales, J., Delson, E. (2015): First record of Mesopithecus (Cercopithecidae, Colobinae) from the Miocene of the Iberian Peninsula. - Journal of Human Evolution, 88:1-14

ANDERSSON, K. (1998): Redescription of the Uppsala material of Metailurus, with a review of the genus. - Master of Science Thesis, Uppsala University, 30 pp.

BAKALOv, P. (1955): Chalicotheriidae in Südwestbulgarien. -Izvestija na Geologicheskia Institut. Bulgarska Akademya na Naukite, 3: 151-159. [in Bulgarian, with German abstract].

BAKAlov, P., Nikolov, I. (1962): Les fossiles de Bulgarie - X - Mammifères tertiaires. Académie des Sciences de Bulgarie, 170 p.

BARYSHNiKov, G., Averyanov, A. (1995): Deciduous teeth of carnivorous mammals (Order Carnivora). Part V. Families Protelidae and Hyaenidae. - Proceedings of the Zoological Institute St. Petersburg, 263: 46-84.

Bernor, R., Tobien, H., HAYeK, L.-A., MitTMann, H.-W. (1997): Hippotherium primigenium (Equidae, Mammalia) from the late Miocene of Höwenegg (Hegau, Germany). - Andrias, 10: $1-230$.

Böhme, M., VAn BaAK ,C., Prieto, J., Winklhofer, M., Spassov, N. (2018): Late Miocene stratigraphy, palaeoclimate and evolution of the Sandanski Basin (Bulgaria) and the chronology of the Pikermian faunal changes. - Global and Planetary Change, 170: 1-19.

Bonis, L. DE, Bouvrain, G., GeraAdS, D., Koufos, G.D. (1990): New remains of Mesopithecus (Primates, Cercopithecidae) from the late Miocene of Macedonia with the description of a new species. - Journal of Vertebrate Paleontology, 10: 473-483.

CODREA V. (1994): A priority issue: Deinotherium proavum Eichwald or Deinotherium gigantissimum Ştefănescu? - In: The Miocene from the Transylvanian Basin, Cluj-Napoca, 105-110. 
Eisenmann, V., Alberdi, M., de Giuli, C., Staesche, U. (1988): Studying fossil Horses. - In: Woodburne, M. \& P. Sondaar (eds.) "New York International Hipparion Conference, 1981", pp 71.

Fuss, J., PRIETO, J., BÖHME, M. (2015): Revision of the boselaphin bovid Miotragocerus monacensis Stromer, 1928 (Mammalia, Bovidae) at the Middle to Late Miocene transition in Central Europe. - Neues Jahrbuch für Geologie und Paläontologie Abhandlungen, 276: 229-265.

GAREVsKi, R., MARKov, G.N. (2011): A Deinotherium gigantissimum (Mammalia, Proboscidea) palate with deciduous dentition from the area of Veles, Republic of Macedonia. Paläontologische Zeitschrift, 85: 33-36.

GASPARIK, M. (2001): Neogene proboscidean remains from Hungary; an overview. - Fragmenta Palaeontologica Hungarica, 19: 61-77.

GERAADS, D., 1974. Les giraffidés du Miocène supérieur de la région de Thessalonique (Grèce). Thèse, 3ème cycle, Université Paris VI - 1-102 (unpublished) Paris.

GeraAds, D., Spassov, N., Kovachev, D. (2005): Giraffidae (Artiodactyla, Mammalia) from the late Miocene of Kalimantsi and Hadjidimovo, South-Western Bulgaria. - Geologica Balcanica, 35: 11-18.

Geraads, D., Spassov, N., Kovachev, D. (2006): The Bulgarian Chalicotheriidae (Mammalia): an update. - Revue de paléobiologie, 25: 429 - 437.

Geraads, D., Spassov, N. Hristova, L., Markov, G.N., Tzankov, T. 2011. Upper Miocene mammals from Strumyani, South-Western Bulgaria. - Geodiversitas, 33: 451-484.

GeRAADS, D., SpASSOV, N. (2009): Rhinocerotidae from the late Miocene of Bulgaria. Palaeontographica A, 287: 99-122.

Gromova, V. (1952): Hipparions (gen. Hipparion). - Trudy Paleontologicheskogo Instituta Akademii Nauk SSSR, 36: 475pp. [in Russian] 
Kojumdgieva, E., Nikolov, I., Nedjalkov, P., Busev, A. (1982): Stratigraphy of the Neogene in the Sandanski graben. - Geologica Balcanica 12; 69-81.

Kostopoulos, D. S. (2005): The Bovidae (Mammalia, Artiodactyla) from the late Miocene of Akkaşdağı, Turkey. - In Sen S. (ed.), Geology, mammals and environments at Akkaşdağl, late Miocene of Central Anatolia. Geodiversitas 27: 747-791.

Kostopoulos, D.S. (2009): The Late Miocene Mammal Faunas of the Mytilinii Basin, Samos Island, Greece: New Collection. 14. Bovidae. - Beiträge zur Palaont., 31: 345-389, Wien. Kostopoulos, D.S. (2016): Palaeontology of the upper Miocene vertebrate localities of Nikiti (Chalkidiki Peninsula, Macedonia, Greece). Artiodactyla. - Geobios 49: 119- 134.

Kostopoulos, D. S. \& Bernor, R. L. (2011): The Maragheh bovids (Mammalia, Artiodactyla): systematic revision and biostratigraphic-zoogeographic interpretation. - Geodiversitas $\mathbf{3 3}$ (4): 649-708. DOI: $10.5252 / g 2011 \mathrm{n} 4 \mathrm{a} 6$.

Koufos, G.D. (1987a): Study of the Pikermi Hipparions. Part I: generalities and taxonomy. - Bull. Mus. Nat. Hist. Nat. C 9 (2): 197-252.

Koufos, G.D. (1987b): Study of the Turolian Hipparions of the Lower Axios Valley (Macedonia, Greece).1. Locality "Ravin Des Zouaves-5" (RZO). - Geobios 20 (3): 293-312.

Koufos, G.D. (2000): Revision of the late Miocene carnivores from the Lower Axios Valley. Münchner Geowissenschaftliche Abhandlungen, A 39: 51-92.

Koufos, G.D. (2006): The Late Miocene Vertebrate locality of Perivolaki, Thessaly, Greece. 4. Carnivora. - Palaeontographica A 276 (1-6 ): 39-74..

Koufos, G.D. (2009): The Genus Mesopithecus (Primates, Cercopithecidae) in the late Miocene of Greece. - Bolletino della Società Paleontologica Italiana, 48 (2): 157-166.

Koufos, G.D (2012): A new protictithere from the late Miocene hominoid locality Ravin de la Pluie of Axios Valley (Macedonia, Greece). - Paläontolologische Zeitschrift 86: 219-229. 
Koufos, G.D., Vlachou, T. (2016): Palaeontology of the upper Miocene vertebrate localities of Nikiti (Chalkidiki Peninsula, Macedonia, Greece) Equidae. - Geobios 49: 85-115.

Kovatchev D. ( 2001): Description d'un squelette complet de Metailurus (Felidae, Carnivora, Mammalia) du Miocène supérieur de Bulgarie. - Geologica Balcanica, 31: 71-88

Kovachev, D. ( 2012): A porcupine skeleton of Hystrix (Hystrix) primigenia (Wagner) from the Upper Maeotian (Turolian) near Hadzhidimovo, SW Bulgaria. - Geologica Balcanica 41(13): 3-20.

LI, Y. (2014): Restudy of Metailurus major from Yushe Basin, Shanxi Province reported by Teilhard de Chardin and Leroy. - Vertebrata PalAsiatica, 52 (4): 467-485.

LI, Y., Spassov, N. (2017): A new species of Paramachaerodus (Mammalia, Carnivora, Felidae) from the late Miocene of China and Bulgaria, and revision of Promegantereon Kretzoi, 1938 and Paramachaerodus Pilgrim, 1913. - Paläontologische Zeitschrift, 3 (91): 409-426.

Merceron, G., Zazzo, A., Spassov, N., Geraads, D., Kovachev, D. 2006. Bovid Paleoecology and paleoenvironments from the Late Miocene of Bulgaria: evidence from dental microwear and stable isotopes. - Palaeogeography, Palaeoclimatology, Palaeoecology, 241: 637-654.

Merceron, G., Colyn, M., GeraAdS, D. (2018): Browsing and non-browsing extant and extinct giraffids: Evidence from dental microwear textural analysis. - Palaeogeography, Palaeoclimatology, Palaeoecology, 505: 128-139.

Nikolov, I. (1975): Neue Fossilienfunde von Familie Chalicotheriidae (Mammalia) aus Bulgarien. Review of the Bulgarian Geological Society, 36: 311-313.

NiKOLOv, I. (1985): Catalogue of the localities of Tertiary Mammals in Bulgaria. - Paleontology, Stratigraphy and Lithology (Sofia), 21 :43-62.

PiCKFORD, M., Pourabrishami, Z. (2013): Deciphering Dinotheriensande deinotheriid diversity. Palaeobiodiversity and Palaeoenvironments, 93 (2): 121-150. 
RoussiaKIS, S. (2002): Musteloids and feloids (Mammalia, Carnivora) from the late Miocene locality of Pikermi (Attica, Greece). - Geobios, 35: 699-719

Salesa, M.J., Antón, M., Turner, A., AlcalÁ, L., Montoya, P., Morales, J. (2010): Systematic revision of the Late Miocene sabretoothed felid Paramachaerodus in Spain. Palaeontology, 53: 1369-1391.

Spassov, N. (2002): The Turolian Megafauna of West Bulgaria and the character of the Late Miocene "Pikermian biome". - Bollettino della Societa Paleontologica Italiana, 41(1): 6981.

Solounias, N. (1981): The Turolian fauna from the island of Samos, Greece. — [in:] HECHT, M. \& SzAlay, F.S. (eds.). Contribution to Vertebrate Evolution. Pp. 1-232, Basel (Karger AG Publ. House).

Spassov, N., BÖHME, M., GeraAds, D., KÖTter, S., van BAAK, C. (2017): Pikermian mammal event, post-Pikermian mammal turnover and appearance of Graecopithecus. - 5th Congress of the RCMNS. September 03-06.2017. Book of Abstracts, p. 21.

Spassov, N., GeRAADS, D. (2004): Tragoportax Pilgrim and Miotragocerus Stromer (Mammalia, Bovidae) from the Turolian of Hadjidimovo, Bulgaria, and a revision of the Late Miocene Mediterranean Boselaphini. - Geodiversitas, 26 (2): 339-370.

Spassov, N., GeraAds, D. (2015): A new felid from the late Miocene of the Balkans and the contents of the genus Metailurus Zdansky, 1924 (Carnivora, Felidae). - Journal of Mammalian Evolution, 22: 45-56.

Spassov, N., Geraads, D., Hristova, L., Markov, G.N., Merceron, G., Tzankov, T., Stoyanov, K., BöHME, M., Dimitrova, A. (2012): A hominid tooth from Bulgaria: The last pre-human hominid of continental Europe. - Journal of Human Evolution 62: 138-145. 
Spassov, N., TZANKov, TZ., GeraADS, D. (2006): Late Neogene stratigraphy, biochronology, faunal diversity and environments of South-West Bulgaria (Struma river valley). - Geodiversitas, 28(3): 477-498.

Spassov, N., GeraAds, D., Hristova, L., Markov, G. (2018): The Late Miocene mammal faunas of the Republic of Macedonia (FYROM). - Palaeontographica A, 311(1-6): 1-85.

Tzankov, T., SPAssov, N., Stoyanov, K. (2005): Neogene-Quaternary Paleogeography and Geodynamics of Middle Struma River Valley Area (S.-W. Bulgaria). - South-West University “N. Rilski”, Blagoevgrad, 199 p. (English summary).

Vlachou, D., Koufos, G.D. (2006): The late Miocene vertebrate locality of Perivolaki, Thessaly, Greece, 6. Equidae. - Palaeontographica 276: 81-119.

ZAGORCHEV, I. (2007): Late Cenozoic development of the Strouma and Mesta fluviolacustrine systems, SW Bulgaria and northern Greece. - Quaternary Science Reviews, 26: 2783-2800.

ZAPFe, H. (1991): Mesopithecus pentelicus Wagner aus dem Turolien von Pikermi bei Athen, Odontologie und Osteologie (Eine Dokumentation). - Neue Denkschriften des Naturhistorischen Museums in Wien, pp. 203.

ZHANG Z-Q. (2005): Late Miocene Boselaphini (Bpovidae, Artiodactyla) from Fugu, Shaanxi Province, China. - Vertebrata PalAsiatica, 7: 208-218.

Addresses of the authors:

Nikolai Spassov, National Museum of Natural History, Bulgarian Academy of Sciences, Tsar Osvoboditel 1, 1000 Sofia, Bulgaria; e-mail: nspassov@nmnhs.com Denis Geraads, CR2P - MNHN, CNRS, UPMC, 8 rue Buffon, 75231 PARIS CEDEX 05 e-mail: denis.geraads@mnhn.fr 
Latinka Hristova, National Museum of Natural History, Bulgarian Academy of Sciences, Tsar Osvoboditel 1, 1000 Sofia, Bulgaria;

e-mail: latihristova@abv.bg

Georgi Markov, National Museum of Natural History, Bulgarian Academy of Sciences, Tsar Osvoboditel 1, 1000 Sofia, Bulgaria;

e-mail: $\underline{\text { markov@nmnhs.com }}$

Table captions

Table 1. Mesopithecus from Gorna Sushitsa. Comparative upper tooth metric data (comparative data from: BONIS et al. 1990; ZAPFE 1991; KOUFOS et al. 2003; SPASSOV et al. in press and personal data). Table 2. Mesopithecus from Gorna Sushitsa. Comparative mandibular dimensions (comparative data from: BonIS et al. 1990; KoufOS 2006; SPASSOV et al. in press and personal data).

Table 3. Mesopithecus from Gorna Sushitsa. Comparative lower tooth metric data (comparative data from: BonIS et al. 1990; ZAPFE 1991; KOUFOS et al. 2003; KOUFOS 2006; SPASSOV et al. in press and personal data).

Table 4. Mesopithecus from Gorna Sushitsa. Comparative metric data for male (Table 4.1.) and

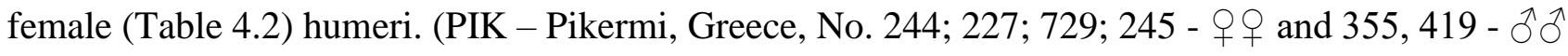
from the coll. of MNHN, orig. data; HD - Hadjidimovo, Bulgaria; KAL - Kalimantsi, Bulgaria.) Table. 5. Comparative skull and upper tooth dimensions of Ictitherium cf. viverrinum from Gorna Sushitsa (left column: dimensions of the specimen GS2-3165; right column: min.-max. values for $I$. viverrinum (after Semenov 1989).

Table 6. Comparative mandibular and tooth dimensions of Plioviverrops in mm. :KK - Kiro Kuchuk, R. of Macedonia; KAL - Kalimantsi site (loc. Burdovski pat), Bulgaria; PIK - Pikermi, Greece (after 
SPASSOV et al. in press); PER - Perivolaki (after Koufos 2006); Axios - Vathylakkos and Ravin des Zouaves (after Koufos 2000)

Table 7. Mandibular and lower tooth dimensions (in mm) of ?Hyaenotherium magnum (GS2-3154 ). Comparative dimensions for H. magnum from SEMENOV (1989).

Table 8. Comparative mandibular and dental metric data for Metailurus major.

Table 9. Comparative mandible and Table 10 tooth dimensions of Paramachaerodus (explanation of the abbreviations after LI \& SPASSOV 2017; MDp3/4 - mandible depth under p3/p4 contact; measurements for P. transasiaticus after LI \& SPASSOv 2017; P. ogygia and P. maximiliani after SALESA et al 2010; P. orientalis: measurements of the type of Machairodus schlosseri WEITHOFFER, 1888 from Pikermi (from SALESA et al. 2010 and after cast kindly sent to N.S. by D. NAGEL, Inst. of Paleontology, Vienna).

Table 11. Tragoportax and Pikermicerus upper tooth metric data (comparative data from SPASSOV \& GERAADS 2004 and personal data) (HD - Hadjidimovo).

Table 12. Measurements of boselaphine lower tooth-rows (comparative data from SPASSOV AND GERAADS 2004 and personal data).

Table 13. Comparative dimensions of Tragoportax amalthea skull from Gorna Sushitsa. 13.1 - horn core's dimensions. 13.2 - Skull dimensions. (Comparative data from SPASSOV \& GERAADS 2004). Table 14. Measurements of some large antelopes, arranged in decreasing Pm/M index Table 15. Measurements of medium size bovid dentitions.

Table 16. Measurements of medium-size bovid horn-cores and frontlets.

Table 17. Measurements of hipparion skulls from Gorna Sushitsa localities, in mm.

1., muzzle length, prostion-middle of the line connecting the anterior borders of P2; 2 . palatal length, middle of the line connecting the anterior borders of P2 to anterior border of choane; 7. premolar length; 8 . molar length; 9 . upper cheek teeth length; 14 . minimal muzzle breadth; 15 . muzzle breadth at I1-I1; 32, distance orbit-preorbital fossa (POF); 33. length of PF; 35. height of POF (perpendicular 
to 33); 36. distance ventral border of POF-crista facialis; O-P2. distance from the anteriormost point of the orbit to the anterior end of $\mathrm{P} 2$.

Table 18. Measurements of the Equid metacarpals from Gorna Sushitsa, in mm.

1. maximal length; 3. minimum width of shaft; 4. depth of shaft; 5. proximal articular breadth; 6 . proximal articular depth; 7. Maximal diameter of the articular facet for third carpal (magnum); 8. diameter of the anterior facet for the fourth carpal (unciform); 10. distal maximum supra-articular breadth; 11. distal maximum articular breadth; 12. distal maximum depth of the keel; 13. distal minimum depth of the lateral condyle; 14. distal maximum depth of the medial condyle.

Table 19. Measurements of the Equid metatarsals from Gorna Sushitsa, in mm.

1. maximal length; 3. minimum width of shaft; 4. depth of shaft; 5. proximal articular breadth; 6 . proximal articular depth; 7. Maximal diameter of the articular facet for the third tarsal (cuneiforme 3); 8. diameter of the anterior facet for the fourth tarsal (cuboid); 10. distal maximum supra-articular breadth; 11. distal maximum articular breadth; 12. distal maximum

Table 20. Measurements of Ancylotherium Mt IVs.

Table 21. Distribution of taxa in Gorna Sushitsa localities.

\section{Figures}

Figure 1. Map of Gorna Sushitsa fossiliferous site.

Figure 2. Mesopithecus and Hystrix from Gorna Sushitsa. A - A right subadult maxillary fragment of M. pentelicus (GS8-2687) with P2-M3 (M3 is not completly erupted); B-D - a male mandible from GS11 (cast), stored in UT (DG); B: left lateral view; C: occlusal view; D: rostral view; EF - mandible of an old female GS8-2685; E: right lateral views; F: occlusal view; G - a mandible of an adult individual, GS8-3686; H - left female humerus GS11 (UT(DG); I - male right distal humerus GS4-3150; J - calcaneus (GS7-3195A); K - talus (GS7-3195B); L - calcaneus GS2-2566 of Hystrix primigenia. Scale bar $=10 \mathrm{~mm}$ for A, G, E, F, J and K; = $20 \mathrm{~mm}$ for B, C, D, H, I and L. 
Figure 3a. A-B - Deinotherium gigantissimum DP2d GS9-3257; A: occlusal; B: labial view; CAdcrocuta eximia, GS2-3158, right maxilla fragment with P2-M1, occlusal view; D-E, Ictitherium cf. viverrinum, rostral part of skull (GS2-3165); D: in lateral view; E: in ventral view; F?Hyaenotherium magnum, semimandible, GS2-3154; G-H, Plioviverrops orbignyi, fragment of a semi-mandible (GPIT/MA/ 3634) with p4; G: in lateral view; H: in occlusal view. Scale bar: For A$2=20 \mathrm{~mm}$, for $\mathrm{G}, \mathrm{H}=0.75 \mathrm{~mm}$.

Figure 3b. Some trends in the evolution of Adcrocuta eximia P2-P3 from the Vallesian/Turolian transition to the end of the middle Turolian on the Balkans. A - P3 of Adcrocuta eximia from Bashibos (Vallesian/Turolian boundary) in lingual view (after Spassov et al. 2018). The strong mesial additional cusp and well expressed lingual cingulum are seen, B-C - Adcrocuta eximia from Hadjidimovo (second half of the early Turolian) (coll. KMP); B: HD-9304; C: HD-9310; D - P2-P3 of Adcrocuta eximia GS2-3158; E - Adcrocuta eximia PIK-3000 from Pikermi (Middle Turolian) (coll. MNHN); F - Microstonyx, M3, FM 3509 GS10; G-H - Propotamochoerus GS8-2691; G: buccal view; H: occlusal view; I - Microstonyx, m3 GS2-8288. A-E = reduced to the same overall length; $\mathrm{F}=$ scale $\mathrm{x} 1, \mathrm{G}-\mathrm{I}=$ scale $\mathrm{x} 2$.

Figure 4. A - Metailurus major, GS10-3511, fragment of mandible dex. with p3-m1; B-C Machairodus aff. (Amphimachairodus) giganteus left DP3; B: lingual view; C: occlusal view; D-E Paramachaerodus orientalis, left semimandible (GS2-3157); D: in lateral view; E: in medial view; F-H - comparison of the lingual view of the carnassial tooth of three Paramachaerodus species; F: Pikermi; G: Paramachaerodus orientalis GS2-3157 Gorna Sushitsa; H, Paramachaerodus transasiaticus HD9228 Hadjidimovo. Scale bar for A=15 mm, for B, C=10mm, for D, E-20 mm, E-H out of scale.

Figure 5. Size variation in DP2, D. gigantissimum. Modified after GAREVSKI \& MARKOV (2011). Figure 6a. A-B - Cranial fragment of Cremohipparion mediterraneum GS3- 2696; A: lateral view; B: occlusal view of the left tooth row; C-D - cranial fragment of Cremohipparion mediterraneum GS3- 
2695; C: lateral view; D: occlusal view; E-H - Tragoportax amalthea (GS8-2638); E: occlusal view of the upper tooth row; F: frontal view; G: semi-lateral view; H: lateral view. Scale bar=20mm for A, B, C, D and E; F, G and $\mathrm{H}$ out of scale.

Figure 6b. A-F - Comparative morphology of the mesial part of the second upper premolar of Tragoportax from Gorna Sushitsa. A, T. rugosifrons (Hadjidimovo, HD-3664, coll. KPM) upper premolars; B: T. rugosifrons (Hadjidimovo, HD-2292, coll. KPM) upper premolars; C: Tragoportax cf. amalthea (GS2-2806) upper premolars; D: Tragoportax amalthea (GS2-2638) upper premolars; E: Tragoportax amalthea (Pikermi, PIK-2359, coll. MNHN) upper premolars; F: Tragoportax amalthea (Pikermi, PIK-2357, coll. MNHN) upper premolars; G-H - cf. Skoufotragus laticeps GPIT-MA 3599; G: frontal view (position of the left horn-core restored); H: lateral view. A-F reduced to the same overall length; G-H - out of scale.

Figure 7. Bovidae from Gorna Sushitsa. A - Palaeoryx ? sp., incomplete frontlet GS4-3517, left lateral view; B - C Prostrepsiceros rotundicornis, fontlet GS3-2830; B: front view; C: left lateral view; D - Palaeoreas lindermayeri, left lower tooth-row GS8-2907; E - Oioceros rothi, left lower tooth-row GS8-2906; F - Prostrepsiceros rotundicornis, left lower tooth-row GS8-2622; G Tragoportax sp., left lower tooth-row GS8-2647; H - Gazella cf. capricornis, partial muzzle GS72853; I - Oioceros rothi, frontlet GS3-2829. Scale bar = $5 \mathrm{~cm}$ for Figs E-F; $10 \mathrm{~cm}$ for Figs D, G, H; $20 \mathrm{~cm}$ for Figs A, B, C, I.

Figure 8. Basal dimensions of Palaeoreas lindermayeri horn-cores. Those from Gorna Sushitsa, Kalimantsi, and Pikermi are distinctly smaller than those from Hadjidimovo.

Figure 9. Perissodactyla from Gorna Sushitsa. A - B Acerorhinus sp., skull GS7-3142; A: dorsal view; B: ventral view; C - Ceratotherium neumayri ?, DP1-DP3 GS8-2912; D - F- Ancylotherium pentelicum, Mt IV GS7-2584; D: front view; E, medial view; F, proximal view; G - Anisodon ? sp., DP3-DP4 GS10-3514. Scale bar $=40 \mathrm{~cm}$ for Fig. A, $20 \mathrm{~cm}$ for Figs. C, D-F $5 \mathrm{~cm}$ for Fig. G. 